\title{
Benzedeiras e benzedeiros quilombolas - construindo identidades culturais
}

\author{
Benzedeiras and benzedeiros quilombolas - building cultural identities
}

\section{Benzedeiras et benzedeiros quilombolas - bâtir des identités culturelles}

\author{
Benzedeiras y benzedeiros quilombolas - construyendo identidades culturales
}

\author{
Dulce Santoro Mendes ${ }^{1}$ \\ Claudio São Thiago Cavas ${ }^{1}$
}

Recebido em 07/04/2017; revisado e aprovado em 23/06/2017; aceito em 02/07/2017

DOI: http://dx.doi.org/10.20435/inter.v19i1.1568

\begin{abstract}
Resumo: Este artigo é um recorte do projeto de pesquisa em andamento e propõe uma reflexão teórica acerca dos processos de construção das identidades culturais de benzedeiras e benzedeiros moradores de comunidades quilombolas, sob o enfoque dos estudos culturais e pós-coloniais. As práticas tradicionais e as religiosidades sincréticas, que moldam os cosmos particulares dessas mulheres e homens, promovem o movimento dialógico que oferece os elementos importantes para a formação das identidades coletivas das suas comunidades.
\end{abstract}

Palavras-chave: identidades culturais; benzedeiras e benzedeiros quilombolas; religiosidades.

Abstract: This article is a reflection of the ongoing research project and proposes a theoretical reflection about the processes of construction of the cultural identities of benzedeiras and benzedeiros living in quilombola communities under the focus of cultural and postcolonial studies. Traditional practices and syncretic religiosities, which shape the particular cosmos of these women and men, promote the dialogical movement that offers the elements important for the formation of the collective identities of their communities.

Keywords: cultural identities; benzedeiras and benzedeiros quilombolas; religiosities.

Résumé: Cet article est un projet de recherche de la coupe en cours, et propose une réflexion théorique sur les processus de construction de l'identité culturelle et les guérisseurs benzedeiros résidents des communautés quilombos dans le centre d'études culturelles et postcoloniales. Les pratiques traditionnelles et syncrétique religiousness qui façonnent le cosmos particulier de ces femmes et les hommes, promouvoir le mouvement dialogique qui offre les éléments importants pour la formation des identités collectives de leurs communautés.

Mots-clés: identités culturelles; benzedeiras et benzedeiros quilombolas; religiosité.

Resumen: Este artículo es un recorte del proyecto de investigación en curso, y propone una reflexión teórica a cerca de los procesos de construcción de las identidades culturales de benediceras y bendecidentes moradores de comunidades quilombolas bajo el enfoque de los estudios culturales y postcoloniales. Las prácticas tradicionales y las religiosidades sincréticas, que moldean los cosmos particulares de estas mujeres y hombres, promueven el movimiento dialógico que ofrece los elementos importantes para la formación de las identidades colectivas de sus comunidades.

Palabras clave: las identidades culturales; benzedeiras y benzedeiros quilombolas; religiosidad.

\section{INTRODUÇÃO}

As benzedeiras e os benzedeiros são cuidadores dos males físicos e espirituais dos moradores das comunidades quilombolas e, diariamente, são convocados para resolver de briga de casais às bênçãos aos animais, além de cuidarem de doenças que, no geral, se encontram fora do escopo de tratamento pela medicina dogmatizada. Da identificação das moléstias ao tratamento com rezas, chás, banhos e unguentos preparados com as ervas colhidas especificamente, para cada caso, nos quintais de suas casas, utilizam-se de seus saberes tradicionais repassados pela oralidade através de gerações.

\footnotetext{
${ }^{1}$ Universidade Federal do Rio de Janeiro (UFRJ), Rio de Janeiro, Rio de Janeiro, Brasil.
} 
Às práticas tradicionais empregadas pelas benzedeiras e benzedeiros quilombolas, na promoção da cura e proteção, alia-se uma religiosidade sincrética pelas influências culturais das matrizes africanas, católicas e indígenas, produto dos contextos históricos específicos que marcam o povo brasileiro. $\mathrm{O}$ sincretismo religioso atribuído às mulheres e aos homens benzedeiros quilombolas, não se dá na mesma medida para todas e todos, mas as primeiras observações do campo revelaram que maioria delas e deles se declara pertencente à religião católica, embora suas práticas, as imagens dos santos canonizados ou não, além das representações de outras divindades mantidas em seus âmbitos domésticos, demonstrem a convivência pacífica entre elementos de proveniências religiosas diversas.

Em comunidades quilombolas contemporâneas, as adaptações dão continuidade às práticas tradicionais dos antigos quilombos, condicionando diretamente a vida cotidiana das populações moradoras (SILVA, 2010). As práticas socioculturais envolvendo diferentes circunstâncias, concepções, opiniões e valores estabelecidos no âmbito da "medicina popular" se constituem em um arsenal de técnicas, conhecimentos e práticas (OLIVEIRA; COSTA JÚNIOR, 2011) colocadas à disposição de quem precisa, sendo, por isso, consideradas formadoras das identidades individuais e coletivas.

Com a urgência da definição de identidades no contexto pós-colonial, a questão assume relevante importância no Brasil, a partir de 1980, quando os movimentos sociais ganharam força na discussão sobre o tema na luta contra a desigualdade social e contra os preconceitos, inclusive, o racial. A população negra e pobre inserida multiplamente em categorias desvalidas e rejeitadas, que requer um lugar que não seja o de dominados, oprimidos e discriminados pela modernidade ocidental, luta na atualidade para que seus indivíduos se posicionem como sujeitos de sua história (CARVALHO, 2011), através da construção social de uma identidade cultural, que passou a ser o caminho viável para sair da invisibilidade em que foi colocada no cenário nacional.

Nesse sentido, o desafio teórico da proposta de pesquisa constituir-se-á em analisar as inserções culturais dos indivíduos em múltiplas pertenças coexistentes no mesmo território simbólico, onde o círculo formado pelas identidades religiosas sincréticas das benzedeiras e benzedeiros é inserido no círculo formado pela dimensão étnica racial quilombola.

As benzedeiras e os benzedeiros quilombolas carregam consigo as marcas identitárias que os constituem em sujeitos da ação reivindicatória da luta por direitos e acesso às políticas públicas, como é o caso das comunidades que serão foco do estudo em andamento. Teoricamente, as identidades culturais assumidas passam a responder pelas identidades construídas coletivamente e submetidas às condições específicas das trajetórias históricas de cada grupo, utilizando a memória e as experiências vividas pelas benzedeiras e benzedeiros nas comunidades.

Nesse sentido, é de se supor que a identidade e a memória sejam construções profundamente imbricadas e que, sendo evocadas, entre outros pilares fundacionais das lutas quilombolas, contribuirão para a geração de novos sentidos que sustentem os processos de reelaboração cultural.

As comunidades quilombolas constituem-se, hoje, em categoria jurídica revestida de estereótipos e preconceitos, e são marcadas por primitivismo e voltadas para um passado de servidão (MORENO, 2013). A complexidade das questões intrínsecas, aos estudos das identidades culturais em comunidades quilombolas, tem residido na abordagem teórico-metodológica sob a perspectiva pós-colonial, sem perder de vista a discussão das "implicações epistemológicas da virada descolonial" (GROSFOGUEL, 2008) para a análise dos conceitos contidos nos paradigmas dos estudos culturais, como base teórica da pesquisa proposta. 
Entre outras questões, o estudo pretende responder à questão: qual o papel desempenhado pelas benzedeiras e benzedeiros quilombolas na construção das identidades culturais coletivas e na coesão do grupo nos contextos atuais dos movimentos sociais de luta por direitos dessas populações?

Trabalhar coletivos humanos em psicossociologia de comunidades sob a perspectiva dos estudos culturais e pós-coloniais irá requerer visões transversais entre diferentes campos do conhecimento, assim como a utilização de métodos científicos interdisciplinares. Após maiores períodos de observação do campo de pesquisa, a metodologia proposta para o seu desenvolvimento elege o cunho qualitativo para a análise das entrevistas narrativas (BAUER; GASKELL, 2013), orientadas por um roteiro semiestruturado e registradas em áudios, vídeos e fotografias. As entrevistas irão apoiar a interpretação dos acontecimentos nas comunidades, a partir da "perspectiva dos informantes, tão diretamente quanto possível" (BAUER; GASKELL, 2013).

O tratamento das informações levantadas no campo de pesquisa consistirá na análise de conteúdo das narrativas das benzedeiras e benzedeiros quilombolas. Após a transcrição das entrevistas, os trechos referentes às categorias analíticas que emergirem serão utilizados na montagem de um referencial de codificação (BAUER; GASKELL, 2013), que, após condensações textuais sucessivas, resultarão nas palavras-chave.

\section{CONSTRUINDO AS IDENTIDADES CULTURAIS DAS BENZEDEIRAS E DOS BENZEDEIROS QUILOMBOLAS}

Benzer é o ato de tornar bento e, segundo Houaiss (2010), na liturgia católica o verbo transitivo direto tem, dentre outros significados, o de invocar, traçando o sinal da cruz no ar, ou ainda santificar ou consagrar (coisa ou pessoa) ao culto de Deus, ser favorável a, abençoar, bem-fadar. Presente nas culturas desde a Antiguidade, a benzeção se constitui em uma relação entre o sobrenatural e a medicina popular historicamente construída (DEL PRIORI, 1997), e se estabeleceu como prática que ultrapassou os tempos através da oralidade, abarcando elementos e recursos culturais próprios dos povos em que foi praticada e, segundo os quais, tendeu a dar importância ou centralizar objetos significativos representantes dos cosmos particulares reconfigurados. Na cultura da benzeção, o corpo não se separa do espírito, portanto as doenças físicas são tratadas como males espirituais.

As benzedeiras e os benzedeiros quilombolas são figuras respeitadas e reconhecidas em suas comunidades, e constroem, em torno de si, um cosmo religioso particular, que demonstra as várias influências no quadro imaginário e ritualístico da religiosidade brasileira. A visão de mundo de cada uma delas e deles contribui com ensinamentos para o dia a dia comunitário. Nas comunidades quilombolas, as identidades culturais são reelaboradas no seio da luta por melhores condições de vida, e as visões de mundo dessas mulheres e homens fazem parte dessa construção mútua. A identidade quilombola é produtora de "coesão social" (DURKHEIM, 1989), pelo reconhecimento que cada indivíduo tem de si, ao mesmo tempo, que se vê diferente do outro, mas que, no entanto, identificou nele "pontos de confluência" a partir dos quais se formam as identidades coletivas (HALL, 2011).

Hall (2011) afirma que as identidades culturais "são cambiantes e diferentes a cada momento", sem que isso invalide a coabitação delas no "mesmo indivíduo". Mas, no pensamento do sociólogo jamaicano, os conceitos de pertencimento às culturas étnicas, raciais, linguísticas 
e religiosas descentram, deslocam e fragmentam o sujeito, impondo mudanças estruturais às sociedades já estilhaçadas pelas paisagens culturais de gênero, classe, sexualidade, etnia, raça e nacionalidade, que antes se constituíam em porto seguro do indivíduo social pós-moderno. $\mathrm{Na}$ sua concepção, as identidades se formam pela modificação e se impõem pela continuidade dos diálogos entre os mundos culturais exteriores e as outras identidades dos sujeitos, que necessitam promover uma espécie de "costura" entre si mesmos e a estrutura social, o que estabilizaria a ele e aos mundos culturais que o habitam (HALL, 2011).

Nesse diálogo com Hall, somos alertados para o fato dos movimentos sociais quilombolas aceitarem a identidade imposta pela emergência das necessidades, o que promove a "erosão das identidades mestras" (HALL, 2011), ao sucumbir ao dinamismo político cultural impondo o jogo das identidades, interferindo na forma como os sujeitos são representados, transformando a política da identidade em política da diferença, que fecha fronteiras em torno do grupo, tal qual uma armadilha, desfecho comum em dias globalizados.

À primeira vista, o aviso de Hall (2011), aplicado às comunidades quilombolas, parece não considerar que "a identificação não é uma afirmação de uma identidade pré-dada, a priori, mas sim, a produção de uma imagem de identidade e a transformação do sujeito ao assumir aquela imagem" (MORENO, 2013). E, nesse sentido, o que estaria por trás das identidades assim definidas seria o conceito de "lugar discursivo e disciplinar" (BHABHA, 1998) utilizado de forma estratégica e institucional para respaldar as discussões sobre as identidades na atualidade.

Esse debate tem permeado os acontecimentos em torno das questões sobre o reconhecimento das comunidades quilombolas, já que essas localidades preexistiam no território como comunidades rurais de agricultores pobres e que passaram a reivindicar a identidade quilombola como posicionamento político. Os acontecimentos diários nas comunidades quilombolas, acompanhados em "tempo real" pela redução da escala global à local, passaram a integrar o sistema mundo, e as benzedeiras e benzedeiros quilombolas, inseridos politicamente nesses processos, continuam a buscar uma identidade que os traduza, no sentido de Hall (2011), ultrapassando as fronteiras na busca de sentido entre as identidades culturais coletivas e individuais a partir de elementos reconhecíveis em uma e outra.

Nesse sentido, a identidade coletiva quilombola se assume como um sistema de identidades, que se tornou mais diversificado, mais flexível quanto ao seu caráter constitutivo, e cada vez mais voltado para as soluções dos problemas dos mais básicos aos mais complexos dos grupos sociais. Os sujeitos quilombolas que compõem esse sistema de identidades, se relacionam entre si, tanto em níveis externos quanto internos (HALL, 1992). Como seres sociais, a partir das características presentes em seus níveis internos, têm valores morais e éticos associados aos seus nomes e aparências e, em nível externo, a forma de se relacionar com o ambiente, com o território que ocupam e com outros grupos em seu entorno. Mas a ligação simbólica e inexorável entre os moradores e o território tradicionalmente ocupado é o elemento mais significativo da construção das identidades coletivas das sociedades quilombolas.

Os territórios são considerados como tradicionais quando nele se desenvolvem relações indissociáveis e profundamente imbricadas entre a sociedade e a natureza na produção de interações simbólicas, equilibrando os homens entre si, e eles com terra. Segundo o decreto oficial do governo brasileiro, as comunidades tradicionais são definidas como "grupos culturalmente diferenciados e que se reconhecem como tais, que possuem formas próprias de organização social, que ocupam e usam territórios e recursos naturais como condição para sua reprodução

INTERAÇÕES, Campo Grande, MS, v. 19, n. 1, p. 3-14, jan./mar. 2018. 
cultural, social, religiosa, ancestral e econômica, utilizando conhecimentos, inovações e práticas gerados e transmitidos pela tradição" (BRASIL, 1988).

Os conhecimentos de manejo e de emprego dos recursos naturais de forma sustentável pelas benzedeiras e benzedeiros quilombolas os colocam em situação de destaque quanto à tradicionalidade, no repasse de costumes, crenças, ritos e lendas através das gerações. Os usos cotidianos, na lida da roça ou específicos na prática religiosa, são conhecimentos tradicionais aprendidos de seus ancestrais e repassados pela oralidade aos seus descendentes. As práticas tradicionais das benzedeiras e dos benzedeiros quilombolas conferem a elas e eles um papel social importante e de referência para seu grupo social, por fazerem parte das situações diárias do convívio comunal, o que os inscreve entre os que percebem a vida sob um ponto de vista particular pela percepção extrassensorial na re-ligação ${ }^{2}$ com o território da sua ancestralidade.

A perspectiva simbólica presente nessas relações constroem laços de pertencimentos mútuos e dialéticos. Pertencer ao território é mais do que tê-lo, é sê-lo. É, nesse sentido, que as atuais discussões sobre os direitos de posse dos territórios ocupados há gerações por famílias quilombolas contribuem para mantê-los ligados à terra que lhes pertence por direito, da qual retiram seu sustento e onde está guardada a memória dos seus ancestrais. Muito mais razão terão as benzedeiras e os benzedeiros quilombolas já que, para elas e eles, a ligação com a terra e com os recursos da natureza fazem parte das suas cosmovisões e dos seus sistemas de crenças.

Normalmente, de origem humilde, as benzedeiras e os benzedeiros quilombolas desenvolvem grande sensibilidade no trato dos problemas da comunidade, selecionando as divindades de acordo com a situação vivida, trabalhando os "domínios" dos protetores espirituais associando-os aos contextos que se apresentam, utilizando os sentidos desenvolvidos na apreensão dos detalhes, dos aspectos físicos, das condições sociais e das ligações místicas que se estabelecem entre o suplicante e o protetor. Frequentemente, a mística regional oferece elementos a mais para composição dos cosmos particulares de cada benzedeira ou benzedeiro, conforme acontece na região do nordeste brasileiro. Às representações do Padre Cicero e Frei Damião se misturam as imagens de santos católicos, orixás do candomblé ${ }^{3}$ e entidades de umbanda ${ }^{4}$.

O sincretismo religioso ${ }^{5}$ das benzedeiras e dos benzedeiros quilombolas pode ser considerado como um aspecto resultante da interculturalidade estabelecida no período colonial brasileiro em contextos históricos promovidos pelo encontro entre saberes e fazeres indígenas, africanos e europeus, além de outras contribuições culturais na formação dos seus cosmos particulares.

\section{AS RELIGIOSIDADES DAS BENZEDEIRAS E BENZEDEIROS}

As práticas religiosas populares brasileiras, envolvendo benzimentos, têm origem no período inicial da colonização e se mantiveram, principalmente, sobre uma base cultural religiosa mista presente em comunidades rurais. Antes dos estudos mais aprofundados sobre o tema,

\footnotetext{
$\overline{2}$ Do verbo religar em latim e significa religação. Essa religação se refere a uma nova ligação entre o homem e Deus. É utilizado como sinônimo de religião.

${ }^{3}$ Divindades africanas cultuadas pelos povos falando da língua Yorubá, originários da região noroeste da África.

${ }^{4}$ Religião sincrética originada no Brasil cujo panteão mistura elementos das culturas iniciais que formaram o povo brasileiro.

${ }^{5}$ Normalmente definido como uma mistura de elementos resultando em um terceiro e diferente dos dois primeiros, mas contendo características reconhecíveis dos elementos originais no amálgama resultante (N.A.).
} 
atribuía-se a formação do povo brasileiro ao "mito das três raças" ${ }^{6}$, posteriormente, as pesquisas passaram a discutir como as trocas culturais entre índios e jesuítas no Brasil, assim como as que mesclaram portugueses e africanos, tanto em África quanto em Portugal, ocorreram num período de tempo considerável para haver uma interpenetração cultural (FERRETI, 2014) anterior à chegada em terras brasileiras.

Antes da chegada dos africanos ao Brasil, os índios foram alvo das tentativas de evangelização pelos jesuítas, a exemplo dos tupinambás, que, incentivados a associar a sua mitologia ao catolicismo português como controle e assimilação (VAINFAS, 1999), teriam sido os primeiros a promover o sincretismo religioso em terras brasileiras. A mistura cultural de várias faces e múltiplas combinações (VAINFAS, 1999) teria se iniciado com essa relação, em paralelo ao que acontecia do outro lado do Atlântico, tanto em terras africanas quanto portuguesas, entre o catolicismo europeu medieval e o sistema africano de crenças.

Durante o período missionário religioso jesuíta no Brasil, a mão-de-obra escrava africana já era empregada na capital da metrópole colonial, estando, portanto, lá também, instalado o processo intercultural entre portugueses e africanos, com destaque para as misturas religiosas entre eles. Conforme verificou Calainho (2004), os cultos e ritos africanos se misturaram ao catolicismo português promovendo a circularidade cultural entre as nacionalidades quando os negros eram capturados e levados para Lisboa e, mais tarde, para as colônias europeias espalhadas pelo mundo, deixando nelas, marcas na cultura portuguesa (CALAINHO, 2004).

O amálgama de religiões e costumes ocorrido separadamente encontrou no Brasil ambiente propício para trocas culturais contínuas. O sincretismo religioso, como um aspecto do hibridismo que marca a formação do povo brasileiro, não só misturou as culturas europeia, negra e indígena, conforme o mito-motor sugerido por muitos estudos antropológicos, como também promoveu outros encontros entre culturas que se efetivaram, tanto em Portugal como na Terra de Vera Cruz (MACEDO, 2008).

O conceito de sincretismo associado à dominação colonial há muito tem recebido críticas daqueles que preferem utilizá-lo em substituição ao de hibridismo, que, pelo maior alcance, seria mais adequado aos estudos sobre as religiosidades brasileiras, entendidas como receptáculo de dimensões culturais mais amplas que somente aquelas relativas à religião. A associação do sincretismo à ideia de "aculturação" foi utilizada com base em teorias antropológicas norte-americanas nos anos de 1950, quando junto com o conceito de sincretismo, avaliaram positivamente os graus de integração entre culturas diferentes (FERRETI, 2014).

No entanto o mau uso histórico do conceito de sincretismo aproximou-o da noção de mistura, transformação, deterioração de culturas, que teria perdido pureza e autenticidade e, por isso, passou a ser um conceito rechaçado pelos religiosos de denominações mais radicais por um lado, e, por outro lado, por teóricos adeptos do conceito de hibridismo como uma versão mais ampla e pós-moderna do mesmo conceito.

Canclini (2003) foi o teórico pioneiro na discussão sobre o hibridismo, que preferiu denominar de hibridação, considerando-o um conceito libertário, fertilizador e criativo, próprio para aplicação na análise de sociedades multiculturais como as surgidas na América após o projeto colonizador europeu. Entre sincretismos e hibridismos culturais e suas polêmicas aplicações,

\footnotetext{
${ }^{6}$ Noção desenvolvida a partir das ideias de Darcy Ribeiro sobre ser a formação do povo brasileiro proveniente de europeus, negros e índios (N.A.).
} 
Stuart Hall (1992) promoveu a conciliação entre os polos da discussão afirmando que esses conceitos produziram novas formas de cultura apropriadas à modernidade tardia, mas para Ferreti, em contrapartida, geraram custos e relativismo, perda de tradições locais e aumento dos fundamentalismos (FERRETI, 2014).

De fato, não é fácil considerar que o contato continuado entre culturas diversas não tivesse ocasionado nenhum tipo de modificação nos sistemas centrais de cada uma delas. O contato, por vezes, pode ter gerado mais ou menos influência de uma ou outra cultura, segundo um campo de forças estabelecido pelos poderes presentes e observado nos frequentes contatos com as comunidades eleitas para a pesquisa. Se, durante algum tempo e em um determinado ambiente físico e social, as influências culturais europeias serviram de suporte para a inserção de elementos das religiões dos povos subjugados, nem sempre foi assim. Naquelas comunidades, as benzedeiras e benzedeiros quilombolas promovem a negociação cultural entre as várias contribuições das religiões dos africanos, dos indígenas, e dos europeus.

Nesse sentido, percebe-se certa confluência entre os conceitos de sincretismo e hibridismo no campo eleito para esta pesquisa e, por considerarmos como Canclini (2003), que o termo hibridismo abarca outros aspectos importantes da cultura na formação do cosmo religioso das benzedeiras e benzedeiros quilombolas, sendo considerável sua articulação teórica com o campo de trabalho.

Costuma-se dizer que a religiosidade de benzedeiras e benzedeiros quilombolas é sincrética sendo esta a característica mais destacada nos estudos realizados sobre suas práticas. Mas o estudo do hibridismo religioso, entre os moradores de comunidades quilombolas marcados pelas lutas por identidade culturais e por direitos, tem aplicação justificável pela busca do referencial teórico sob a perspectiva sociológica que o considera como "fenômeno social" (NOGUEIRA, 2009) ideal para a compreensão da forma como as benzedeiras e os benzedeiros quilombolas lidam com as misturas e justaposições culturais no contexto de suas necessidades cotidianas.

A sociologia das religiões se propõe a estudar como os "efeitos sociais do "pertencimento religioso" interferem no comportamento e na tomada de decisões do indivíduo" (NOGUEIRA, 2009). Dessa forma, o indivíduo passa a desempenhar um papel que foi definido e organizado pela religião, que interfere no seu pensamento e na sua forma de se ver, tornando-a necessária a ele e ao seu desempenho frente à humanidade. Na teoria de Durkheim (1989), a religião é um "fato eminentemente social" e se configura como a forma de explicar o impossível contextualizado na vida humana (PEREIRA, 2015). Às crenças cabe à construção das representações ou dos "estados de opinião", e aos ritos, a organização dos modos de ação.

Se as religiões interferem na forma de pensar dos sujeitos, exercendo poder sobre eles, a complexidade do estudo das religiosidades nas comunidades quilombolas, como panos de fundo para o estudo proposto, abarcará a possibilidade de desvendar as múltiplas estratégias que as benzedeiras e benzedeiros operacionalizam sob as instâncias inter-paradigmáticas, segundo os seus dogmas e tradições, na formação da consciência coletiva dos moradores e, consequentemente, na construção de identidades culturais compartilhadas pelas comunidades.

Nesses contextos, é que as práticas tradicionais de benzedeiras e benzedeiros quilombolas desenvolveram e mantêm a devoção aos santos católicos, às entidades de umbanda, aos orixás do candomblé, entre outras representações da cultura religiosa popular brasileira. Naquelas comunidades, o hibridismo religioso está presente em forma de cultura popular, misturando especificamente o catolicismo popular com religiões afro-brasileiras e indígenas. Essa forma 
popular de se relacionar com o sagrado é considerada uma das mais tradicionais manifestações existentes no Brasil e, desde o período colonial, tem, como característica central, o culto aos santos.

Os santos ocupam na vida do povo um lugar de destaque representado pela presença de um poder especial e sobre-humano, que penetra em diversos espaços da vida e favorece a proteção diante das incertezas numa estreita aproximação e familiaridade com seus devotos, como observou Lúcia Guerra (2015). Assim, a devoção das benzedeiras e dos benzedeiros quilombolas configurada no complexo imagético de seus altares domésticos, compõe-se dos santos católicos, entidades da umbanda e orixás do candomblé, ladeados por fotografias de parentes mortos e outros objetos, conformando o cosmo religioso de onde provém a força para exercerem o ofício de benzimento e promoverem a intermediação entre os planos divino e material para ajudar a quem os procura.

No complexo sagrado, construído pelas benzedeiras e benzedeiros das comunidades quilombolas, estão presentes, também, os seus protetores e inspiradores: aqueles que revelaram a elas e a eles, o "dom" divino de poder curar. Os altares domésticos escrevem um capítulo à parte, nos estudos da temática da religiosidade popular. Constituem-se em microcosmo particular e têm uma organização específica que reflete as subjetividades místicas das benzedeiras e dos benzedeiros quilombolas.

Nesses altares, os protetores espirituais estão dispostos sem hierarquização aparente e se acomodam lado-a-lado, formando parcerias peculiares de divindades. Em meio àquelas forças representadas por estátuas de gesso ou estampas em quadros, a posição central nos altares domésticos é reservada para a figura de maior devoção entre as benzedeiras e benzedeiros.

Esse universo místico em forma de altares domésticos traduz a autonomia e as subjetividades ampliadas com que as benzedeiras e os benzedeiros quilombolas conduzem suas práticas, que, de certa forma, se constituem em insurgência contra a condição de seres "duplamente coIonizados", ao exercerem uma "cortesia dissimulada" (BHABHA, 1998), e "mesmo sem qualquer intenção de profanação, [se] constitui [em] uma contestação objetiva às religiões dominantes" (BELTRÃO JÚNIOR; NEVES, 2013), assim como também representam uma insurgência contra os sistemas hegemônicos também presentes em suas comunidades.

\section{PRÁTICAS E SABERES TRADICIONAIS NAS COMUNIDADES QUILOMBOLAS}

As práticas e os saberes tradicionais são partes do sistema, que tem como fio condutor as rezas proferidas durante os benzimentos, que conformam o universo religioso produto das transformações vividas nos contextos das comunidades onde se desenvolvem os grupos sociais, segundo trajetórias históricas, fatores culturais, socioeconômicos e ambientais próprios. Em comunidades quilombolas, as benzedeiras e benzedeiros mantêm seus saberes e práticas, segundo o repasse intergeracional, que não é limitado às suas famílias. Em processos de cura e também de proteção, as rezas e benzeduras são acompanhadas de outras ações de prevenção ou limpeza em formas de chás, banhos, defumadores, mezinhas e simpatias.

Muitas vezes, ao mosaico de procedimentos de influências africanas ou indígenas se juntam elementos utilizados pelo padre católico durante as missas. A água benta é aspergida naquele que procurou os benzimentos para se livrar de "olho grande". Por vezes, uma única visita às benzedeiras ou aos benzedeiros não é suficiente para acabar com o mal que acomete 
os necessitados dos seus serviços, e, para esses casos, são receitados chás ou banhos, para a continuidade do tratamento até a próxima visita para ser rezado ou benzido.

As benzedeiras e os benzedeiros conhecem as plantas, as ervas e os vegetais e suas propriedades terapêuticas. Sabem a hora de utilizar as folhas, o caule e a raiz, dependendo do emprego da bebida, que pode ser ingerida quente ou fria para desmanchar, limpar, ações que têm o sentido de expurgar o mal quando utilizadas em banhos ou vomitórios com as mesmas finalidades.

Rezadas em voz baixa, às vezes, de forma imperceptível, outras vezes, um pouco perceptíveis, as súplicas emitidas pelas benzedeiras e benzedeiros quilombolas já não são completamente desconhecidas, pois, na atualidade, diversas pesquisas e trabalhos acadêmicos tratam da cultura da benzeção como temática. Mas nem sempre foi assim, de certa forma, a atmosfera de segredo e misticismo contribuiu para a sua preservação e para a variação regional nos textos, com a inclusão de correspondências simbólicas nativas de cada região, apesar de manterem na estrutura do ritual e das rezas, elementos invariáveis e comuns embora possam ter significados diferentes.

Muitas doenças tratadas pelas benzedeiras e benzedeiros quilombolas não constam da lista de tratamentos da medicina institucionalizada. Para Quintana (2007), na medicina popular, diferentemente da medicina acadêmica, as concepções de doença e de terapêutica estão associadas às visões de mundo, a um conjunto de valores e normas morais, a todo um universo cultural articulado a essas práticas, e se contrapõem àquelas baseadas no "etnocentrismo" ocidental, que as limitam ao cientificismo da medicina de mecanismos químico-biológicos.

Durante algum tempo, atribuiu-se a procura pelos serviços de benzedeiras e benzedeiros a um conjunto de fatores que separam a população do acesso aos serviços de saúde oferecidos normalmente nos centros urbanos. No entanto, a cultura da benzeção está enraizada nas comunidades, sem que se possa negar, com certa razão, a preferência das populações moradoras pelos tratamentos tradicionais aplicados pelas benzedeiras e benzedeiros, já que há certa desconfiança sobre o modo de agir dos médicos, que, muitas vezes, "adotam uma atitude autoritária, desqualificando os pacientes pelas representações que eles têm do seu próprio corpo, da doença e dos princípios de higiene, ou quando os profissionais da saúde atribuem à medicina científica o papel da única capaz de colocar ordem dentro do discurso dos pacientes" (QUINTANA, 2007).

As benzedeiras e os benzedeiros quilombolas afirmam que atendem as pessoas que a(o) s procuram, independentemente, de terem consultado os médicos, ou não, e costumam encaminhar para o sistema de saúde pública aqueles casos considerados fora do alcance de cura pelo benzimento, o que não impede a continuidade do tratamento espiritual em prol da saúde do doente. Mas observa-se, também, que não há reciprocidade de indicação de tratamento espiritual por parte dos médicos.

A solidariedade que caracteriza as benzedeiras e os benzedeiros quilombolas não é a única qualidade que a (o)s destaca como referência social para a sua comunidade. A autonomia que compõe a identidade individual dessas mulheres e homens é oferecida à constituição das identidades culturais coletivas do grupo, e está presente também na orientação de suas práticas tradicionais e seus modos de vida, a ponto de provocar episódios considerados insurgentes e contrários à ordem estabelecida, seja na substituição temporária do "padroeiro oficial do povoado" pelo santo de devoção popular, que livrou da peste, os moradores em tempos remotos, seja na decisão coletiva de retirarem a imagem de Santo Antônio levando-a para a casa de uma das benzedeiras do povoado. 
Os argumentos do pároco responsável pela capela local de que, não havendo quem limpasse o interior da igreja, não poderia permitir que as imagens dos santos continuassem no ambiente. Assim, a população, convencida de que havia outras razões, se apoderou da imagem do santo e carregou-a para a casa.

A conhecida fama de Santo Antônio herdada da mitologia portuguesa colonial, como aquele que é eficiente em encontrar coisas perdidas, inclusive escravos, não interfere na admiração dos quilombolas, e a aparente contradição da devoção pelo santo denominado "caminhante" se alia a outras interações com o sagrado, na formação do cosmo religioso que oferece proteção contra as doenças e epidemias, como é o caso de São Roque. O santo milagreiro temporariamente ocupa o lugar do padroeiro "oficial", por alguns dias do mês de agosto, para receber os pagamentos das promessas, o que renova e atualiza a promessa feita no início do século XX, para que mantenha as mazelas e doenças afastadas daquelas comunidades.

\section{CONSIDERAÇÕES FINAIS}

Este artigo intencionou apresentar algumas reflexões sobre o estudo das identidades culturais de benzedeiras e benzedeiros em comunidades quilombolas, tentando ultrapassar a complexidade teórica de relacionar indivíduos inseridos em círculos culturais de múltiplas pertenças sob as perspectivas dos estudos culturais e pós-coloniais e da diáspora. Sendo um recorte do projeto de pesquisa em andamento, este texto apresenta as primeiras impressões resultantes das frequentes observações das comunidades quilombolas selecionadas para o estudo.

Na sequência, a pesquisa se encaminhará para a fase de coleta de dados em campo, conforme previsto na metodologia proposta, que prevê a emersão das categorias de análise que irão transformar os sujeitos da pesquisa em protagonistas de suas próprias histórias. Entre essas categorias, a autonomia, que é marca da identidade individual das benzedeiras e dos benzedeiros quilombolas, será analisada como traço fundamental no construto das identidades culturais coletivas dos grupos sociais a que pertencem.

O sincretismo religioso representado pelos altares domésticos, que as benzedeiras e os benzedeiros quilombolas mantêm em seus espaços domésticos, comprova a convivência pacífica entre as religiões diferentes, que, no entanto, podem ser trabalhadas no conjunto para a ajuda a quem precisa. A solidariedade é outra tônica comum entre essas mulheres e homens religiosos, que benzem as pessoas e também, os animais, a qualquer dia da semana ou hora do dia ou da noite. Embora a maioria das benzedeiras e benzedeiros se declare católica, utilizam uma mistura religiosa sincrética para benzer, quebrando regras e criando outras independente da lógica ou da falta de lógica que possa existir quando se trata de atender a quem vêm à procura dos tratamentos tradicionais.

Quando as necessidades dos acometidos por moléstias físicas ou espirituais não cessam por intermédio de Nossa Senhora da Conceição ou Santo Antônio, pode ser a hora de chamar pelo Seu Zé Pilintra ou Frei Damião. O importante, para as benzedeiras e benzedeiros das comunidades quilombolas, é ter fé na cura que promovem, aliás, "quem cura é Deus!", elas e eles são somente seus intermediários. 


\section{REFERÊNCIAS}

BAUER, M.; GASKELL, G. Pesquisa qualitativa com texto, imagem e som: um manual prático. 11. ed. Petrópolis, RJ: Vozes, 2013.

BELTRÃO JR., H. R.; NEVES, S. S. O estudo das benzedeiras em Parintins: uma abordagem folkcomunicacional. In: CONGRESSO BRASILEIRO DE CIÊNCIAS DA COMUNICAÇÃO, 26., 2013. Manaus: UFAM, 2013. Disponível em: <intercom.org.br/papers/nacionais/2013/resumos/R8-0112-1.pdf>. Acesso em: 26 jun. 2017.

BHABHA, H. K. Interrogando a identidade. In: O local da cultura. Tradução de Myriam Ávila, Eliana Lourenço de Lima Reis e Gláucia Renata Gonçalves. 2. ed. Belo Horizonte: Ed. UFMG, 1998. p. 77-116.

BRASIL. Constituição. Decreto n. 6040, de 7 de fevereiro de 2007. Brasília, DF, Senado Federal: Centro Gráfico, 1988. Disponível em: <ideiasnamesa.unb.br/upload/mídia/1393524919PCT_Decreto9_ no_6040_07_de_fevereiro_de_2007.pdf>. Acesso em: 26 jun. 2017.

CALAINHO, D. Africanos penitenciados pela Inquisição portuguesa. Revista Lusófona de Ciência das Religiões - Inquisição em África - ano III, n. 5/6, p. 47-63, 2004. Disponível em: <http://revistas.ulusofona. pt/index.php/cienciareligioes/article/view/4578>. Acesso em: 10 jan. 2017.

CANCLINI, N. As culturas híbridas: estratégias para entrar e sair da modernidade. São Paulo: Edusp, 2003.

CARVALHO, M. C. Benzimento e cura na comunidade de São João do Cazumbá. Caos - Revista Eletrônica de Ciências Sociais, João Pessoa, PB, n. 18, p. 72-80, 2011. Disponível em: <http://www.cchla.ufpb.br/ caos/n18/8_Cris_Artigo_caos.pdf>. Acesso em: 7 abr. 2017.

DEL PRIORI, M. História das mulheres no Brasil. São Paulo: Contexto, 1997.

DURKHEIM, E. As formas elementares da religião. São Paulo: Paulino, 1989.

FERRETI, S. Sincretismo e hibridismo na cultura popular. Revista PÓS Ciências Sociais, São Luís, MA, v. 11, n. 21, p. 15-34, 2014. Disponível em: <http://www.periodicoseletronicos.ufma.br/index.php/rpcsoc/ article/view/2867>. Acesso em: 26 jun. 2017.

GROSFOGUEL, R. Para descolonizar os estudos de economia política e os estudos pós-coloniais: transmodernidade, pensamento de fronteira e colonialidade global. Revista Crítica de Ciências Sociais, Coimbra, Portugal, n. 80, p. 115-47, mar. 2008. Disponível em: <www.ces.uc.pt/rccs/includes/download. php?id=982>. Acesso em: 26 jun. 2016.

GUERRA, L. B. Juazeiro do Norte: religiosidade e desenvolvimento. 2015. 101p. Dissertação (Mestrado em Ciência da Religião)- Universidade Lusófona de Humanidades e Tecnologias, Lisboa, Portugal, 2015.

HALL, S. Da diáspora: identidades e mediações culturais. Tradução de Adelaine La Guardia Resende, Ana Carolina Escoteguy, Cláudia Ávares, Francisco Rudiger e Sayonaram Amara. Belo Horizonte: Ed. UFMG, 2011.

A identidade cultural na pós-modernidade. Tradução de Tomaz Tadeu da Silva e Guacira Lopes Louro. Rio de Janeiro: DP \& A, 1992.

HOUAISS, A. Dicionário Houaiss. Dicionário da Língua Portuguesa. 2010. Disponível em: <https://houaiss. uol.com.br/pub/apps/www/v3-0/html/index.htm\#0>. Acesso em: 7 abr. 2017.

MACEDO, E. U. Religiosidade popular brasileira colonial: um retrato sincrético. Revista Ágora, Vitória, ES, n. 7, p. 1-20, 2008. Disponível em: <http://periodicos.ufes.br/agora/article/view/1918/1430>. Acesso em: 26 jun. 2017.

MORENO, D. C. G. Identidade da comunidade quilombola Sítio Veiga no contexto pós-colonial. In: CONGRESSO ALAS CHILE, 29. Santiago, Chile, 2013. Disponível em: <http://actacientifica.servicioit.cl/ biblioteca/gt/GT6/GT6_GadelhaMoreno.pdf>. Acesso em: 3 fev. 2018.

NOGUEIRA, J. G. Sincretismo religioso no Brasil em Casa Grande \& Senzala: influências na religiosidade brasileira (Parte 1). História e- história. Disponível em: <https://www.webartigos.com/artigos/ possibilidades-interpretativas-do-campo-religioso-brasileiro/133147\#ixzz563XHJiZr>. Acesso em: 3 fev. 2018.

INTERAÇÕES, Campo Grande, MS, v. 19, n. 1, p. 1-2, jan./mar. 2018. 
OLIVEIRA, E. C. S.; COSTA JÚNIOR, E. O. Saúde e doença: recursos utilizados em rituais de cura no estado da Paraíba. BIOFAR-Revista de Biologia e Farmácia, João Pessoa, PB, v. 6, n. 1, 2011. Disponível em: <sites. uepb.edu.br/biofar/download/v6n1-2011/as\%C3\%BAde_e_doen\%C3\%A7a.pdf>. Acesso em: 26 jun. 2017.

PEREIRA, R. Durkheim e Lévi Strauss: a escola sociológica francesa e uma análise de aproximações teóricas. Rio de Janeiro: UFRJ: IFCS, 2015.

QUINTANA, A. M. A ciência da benzedura: mau-olhado, simpatias e uma pitada de psicanálise. Bauru, SP: EDUSC, 1999. 226p. Disponível em: <http://www.institutocaminhosoriente.com/Livros/Alberto\%20 Quintana\%20-\%20A\%20CI\%CANCIA\%20DA\%20BENZEDURA.pdf>. Acesso em: 3 fev. 2018.

SILVA, Giselda Shyrley da. Benzedores e raizeiros. Saberes partilhados na Comunidade remanescente de quilombo de Santana da Caatinga- 1940-2011. Revista Mosaico, Goiânia, v. 3, n. 1, p. 33-48, 2010. Disponível em: <ser.pucgoias.edu.br/index/php/mosaico/issue/view/111/showToc>. Acesso em: 26 jun. 2017.

VAINFAS, R. Colonização, miscigenação e questão racial: notas sobre equívocos e tabus da historiografia brasileira. Tempo 8, Niterói, RJ, n. 3, p. 1-12, ago. 1999. Disponível em: <http://www.historia.uff.br/tempo/ artigos_dossie/artg8-1.pdf>. Acesso em: 24 jun. 2017.

\section{Sobre os autores:}

Dulce Santoro Mendes: Geógrafa, mestre em geografia, doutoranda em psicossociologia de comunidades e ecologia social. E-mail: issanilu@gmail.com

Claudio São Thiago Cavas: Psicólogo, Mestre em Psicologia do Trabalho pela Universidade de Paris X, doutor em Psicossociologia pelo Programa de Pós-Graduação EICOS- Psicossociologia de Comunidades e Ecologia Social do Instituto de Psicologia da Universidade Federal do Rio de Janeiro-UFRJ. E-mail: claudiocavas@gmail.com 